\title{
Evaluation of dysphagia in different phenotypes of early and idiopathic Parkinsonism
}

\author{
Al-Amir Bassiouny Mohamed ${ }^{1 *}$ (D), Gharib Fawi Mohamed ${ }^{1}$, Hassan Mohamed Elnady ${ }^{1}$, \\ Mohamed Abdelmoneim Sayed ${ }^{1}$, Ahmed Mamdouh Imam², Megahed Mohamed Hassan² \\ and Sherihan Rezk Ahmed ${ }^{1}$
}

\begin{abstract}
Background: Parkinsonism (PD) is a common neurodegenerative disorders into which dysphagia occurs mainly in the late stage and to a lesser extent in an early stage. Diagnosis of dysphagia particularly in early idiopathic Parkinson's disease (IPD) is important as dysphagia affects the quality of life of patients and most of the patients are unaware of this important symptom.

Method: Fifty-four patients were enrolled in this study presented with early IPD attending to the outpatient clinic of Sohag University Hospital. All PD patients were assessed by using Unified Parkinson's Disease Rating Scale (UPDRS) and modified Hoehn and Yahr scale. IPD patients were classified into tremor dominant (TD) and postural instability/gait disorder (PIGD) phenotypes. Swallowing disturbance questionnaire (SDQ) and fiberoptic endoscopic evaluation of swallowing (FEES) were used to evaluate dysphagia.

Results: Thirty-five percent of patients experienced dysphagia when the patients were questioned, and this percent rises to $40 \%$ on using FEES. The results of SDQ were significantly correlated to the results of more accurate FEES. The percentage of dysphagia was higher in patients with PIGD than TD phenotype. Dysphagia was significantly associated with the mean of the Mini-Mental State Examination (MMSE), UPDRS, and modified Hoehn and Yahr scale.
\end{abstract}

Conclusions: Dysphagia is a prevalent symptom in early IPD and significantly correlated with Parkinsonism phenotype, UPDRS, and modified Hoehn and Yahr scale.

Keywords: Parkinsonism, Dysphagia, Swallowing disturbance questionnaire, Fiberoptic endoscopic evaluation of swallowing

\section{Background}

Parkinson's disease (PD) is a common neurodegenerative disorder with prevalence 140 per 100,000 [1, 2].

Most of the patients with PD develop dysphagia in the late stage of the disease in spite of early pathological changes of brainstem structures [3-6].

Dysphagia in IPD may occur in up to $100 \%$ of the patients in advanced disease stages $[7,8]$ which impairs the quality of life, interferes with medication intake, and

\footnotetext{
* Correspondence: amirmohamed36@yahoo.com

${ }^{1}$ Department of Neurology and Psychological Medicine, Sohag University,

Sohag Governorate, Egypt

Full list of author information is available at the end of the article
}

leads to malnutrition and aspiration pneumonia, which is the major cause of death in PD [9].

A recent meta-analysis showed that the prevalence of oropharyngeal dysphagia is $35 \%$ on using subjective tools like questionnaires, and this percent increases to $82 \%$ by using the more objective measures like FEES [7].

Fiberoptic endoscopic evaluation of swallowing (FEES) is considered one of the gold standard tests for the diagnosis of dysphagia, which can be replaced by a simple questionnaire like SDQ when FEES is not available [10].

Previous studies reported that patients with postural instability/gait disorder (PIGD) have greater problems of swallowing than tremor dominant phenotype (TD) which indicate a positive relationship between dysphagia 
and range of motor skills, including falling, postural instability, and gait dysfunction $[11,12]$.

To the best of our knowledge, most of the studies underestimate the frequency and severity of dysphasia in radiologically documented dysphagia, and the simple, sensitive, and specific bedside tests available for diagnosis of dysphagia in IPD are lacking [13-16].

This cross-sectional study was done to detect dysphagia in early and idiopathic parkinsonism by using SDQ and the more accurate FEES and to evaluate the frequency of dysphagia in different phenotypes of IPD as the early detection of dysphagia reduces bad impact on the quality of life of patients.

\section{Methods}

\section{Patients}

The present observational study was conducted on 54 consecutive PD patients (38 men, 16 women, mean age $62.30 \pm 5.6$ ) whom regularly followed up at the outpatient clinic of the Sohag University Hospital from June 2013 to February 2016. They continued levodopa drugs during the time of the study, and all patients were in the early stages of PD and were evaluated in their best on state.

The work was approved by the Medical Research, Ethical Committee of Sohag Faculty of Medicine on September 7, 2014, with reference number (75). All participants were informed in detail about the investigation, and informed written consent was obtained.

All patients fulfilled the UK Parkinson's Disease Brain Bank criteria for PD [17]. Unified Parkinson's Disease Rating Scale (UPDRS) [18] and the modified Hoehn and Yahr scale [19] were used during on state to evaluate the severity and stage of IPD, respectively. Mini-Mental State Examination (MMSE) [20] was used to evaluate the cognitive status of the patients with IPD.

The following inclusion criteria were applied: Patients fulfilled the UK Brain Bank diagnostic criteria of PD [17], with modified Hoehn and Yahr (modified H\&Y) stage between 1 and 3 to target early Parkinson's disease. Patients with MMS examination $>24$ (as cognitive impairment affects the reliability of SDQ), hearing problems, and pharyngoesophageal local conditions were excluded from this study.

To identify PD phenotypes, patients were classified as tremor dominant (TD), postural instability/gait disorder (PIGD), or indeterminate according to the previously described formula that uses items from the UPDRS where the ratio of the mean UPDRS tremor scores (8 items) to the mean UPDRS PIGD scores (5 items) was used to define TD patients (ratio $\geq 1.5$ ), PIGD patients (ratio $\leq 1$ ), and indeterminate patients (ratios $>1.0$ and $<1.5)$ [21, 22].

\section{Study design and ethics}

This cross-sectional study was carried out on patients with idiopathic PD to evaluate the dysphagia in early stage of PD and to assess dysphagia in different phenotypes of IPD.

\section{Methods}

All patients were evaluated by a neurologist and sent to a speech therapist to evaluate dysphagia by FEES and complete a 15-item questionnaire on swallowing disturbances (Additional file 1) [3]. If the score of swallowing

Table 1 Baseline characteristics of patients with PD

\begin{tabular}{|c|c|c|}
\hline & Mean & $\begin{array}{l}\text { Standard } \\
\text { deviation (SD) }\end{array}$ \\
\hline Age $($ mean $\pm S D)$ & 62.30 & 5.642 \\
\hline \multicolumn{3}{|l|}{ Diagnosis } \\
\hline Disease duration (mean \pm SD) & 4.7 & 2.2 \\
\hline \multicolumn{3}{|l|}{ Disease severity } \\
\hline $\begin{array}{l}\text { Mini-Mental State Examination } \\
\text { (MMSE) }(30=\text { normal) }\end{array}$ & 26.8 & 1.8 \\
\hline \multicolumn{3}{|l|}{$\begin{array}{l}\text { Unified Parkinson's Disease } \\
\text { Rating Scale (UPDRS) }\end{array}$} \\
\hline $\begin{array}{l}\text { UPDRS part II score } \\
(68=\text { severe })\end{array}$ & 15.5 & 8.9 \\
\hline $\begin{array}{l}\text { UPDRS part III score } \\
(108=\text { severe })\end{array}$ & 37.5 & 16.3 \\
\hline \multirow{2}{*}{$\begin{array}{l}\text { Modified Hoehn and Yahr } \\
\text { rating ( } 5=\text { severe) }\end{array}$} & 2.1 & 0.6 \\
\hline & $\begin{array}{l}\text { Number of } \\
\text { patients }\end{array}$ & Percentage \\
\hline \multicolumn{3}{|l|}{ Sex } \\
\hline Male & 38 & 70.4 \\
\hline Female & 16 & 29.6 \\
\hline \multicolumn{3}{|l|}{ Parkinsonism phenotype } \\
\hline Tremor dominant & 46 & 85.2 \\
\hline $\begin{array}{l}\text { Postural Instability } \\
\text { and gait instability }\end{array}$ & 8 & 14.8 \\
\hline \multicolumn{3}{|l|}{ Swallowing disturbance questionnaire } \\
\hline Normal & 35 & 64.8 \\
\hline Dysphagia & 19 & 35.2 \\
\hline Oral phase & 13 & 24 \\
\hline Pharyngeal phase & 6 & 11.1 \\
\hline \multicolumn{3}{|l|}{ FEES } \\
\hline Normal swallowing & 32 & 59.3 \\
\hline Residual & 20 & 37.0 \\
\hline Aspiration & 2 & 3.7 \\
\hline \multicolumn{3}{|l|}{ Salivation scale } \\
\hline Normal salivation & 17 & 31.5 \\
\hline Sialorrhea & 37 & 68.5 \\
\hline
\end{tabular}


disturbance questionnaire (SDQ) is more than or equal to 11 , this indicates dysphagia [3].

Also, speech therapist calculated the drooling score by using Drooling Severity and Frequency Scale (DSFS) Appendix 1 [23].

\section{Objective evaluation of dysphagia by fiberoptic endoscopy}

Evaluation of dysphagia in IPD patients during on state was made by fiberoptic endoscopic evaluation of swallowing (FEES). This FEES was carried out by using fiberoptic nasopharyngolaryngoscope (Model 20045020, Storz, Germany). Two examiners made the examination: a phoniatrician who did the endoscopic examination and a nurse who feed the patient by a spoon. Three types of food were offered: (1) solid component by using bread soaked with yogurt, (2) semisolid using yogurt, and (3) liquid using $100 \mathrm{ml}$ of water colored with green food coloring material (1 g.) The endoscope passed through the nose, choana, and nasopharynx and stopped just below the level of the palate in order to visualize the oropharynx, hypopharynx, and the larynx on a monitor. At the moment of swallowing, the pharyngeal wall collapsed and obliterated the pharyngeal cavity. So, the swallow event could not be seen. However, the examiner can comment on events just before and after the swallow. These are initiation delay/residue, penetration, and aspiration. Detailed comments should focus on (1) initiation delay or residue: in the mouth, vallecullae, pyriform sinuses, or in the pharyngeal walls; (2) penetration: food or liquid entering the airway entrance (above or at the vocal fold level); and (3) aspiration: food or liquid entering the airway to the level of trachea (below the level of vocal folds) [24].

\section{Statistics}

The statistical analysis was performed using the Statistical Package for the Social Sciences (SPSS 20.0, SPSS Inc., Chicago, IL, USA) for windows. Descriptive statistics were done to investigate the general characteristics of the patients. Chi-square was used for correlation between qualitative data while Pearson's correlation was used for continuous data. Student's $t$ test was performed to explore the effect of abnormal swallowing on characteristics of patients with PD. Logistic regression analysis was performed to find out independent predictors of dysphagia. All the results were considered significant when $P<0.05$.

\section{Results}

The mean age of the 54 participants in the study (38 men and 16 women) was 62.3 (age range 51-75 years). We selected our participants in the early stage of the disease with mean disease duration $4.7 \pm 2.2$. The mean of UPDRS part II score and UPDRS part III score was $15.5 \pm 8.9$ and $37.5 \pm 16.3$, respectively, while modified Hoehn and Yahr rating was $2.1 \pm 0.6$.

When the PD patients were questioned, the percentage of dysphagia was $35.1 \%$ particularly the oral phase which nearly doubles the percentage of the pharyngeal phase and this percentage increased to $40.7 \%$ when using the more accurate and objective method (FEES) (Table 1 and Fig. 1).

The mean age of patients with normal swallowing and dysphagia was $63.5 \pm 5.9$ versus $60.5 \pm 4.8$, respectively, with a $P$ value of 0.05 .

Most of the patient with dysphagia have a longer disease duration $(5.3 \pm 2.1)$ than those with normal swallowing $(4.3 \pm 2.1)$ with a $P$ value equal to 0.1 .

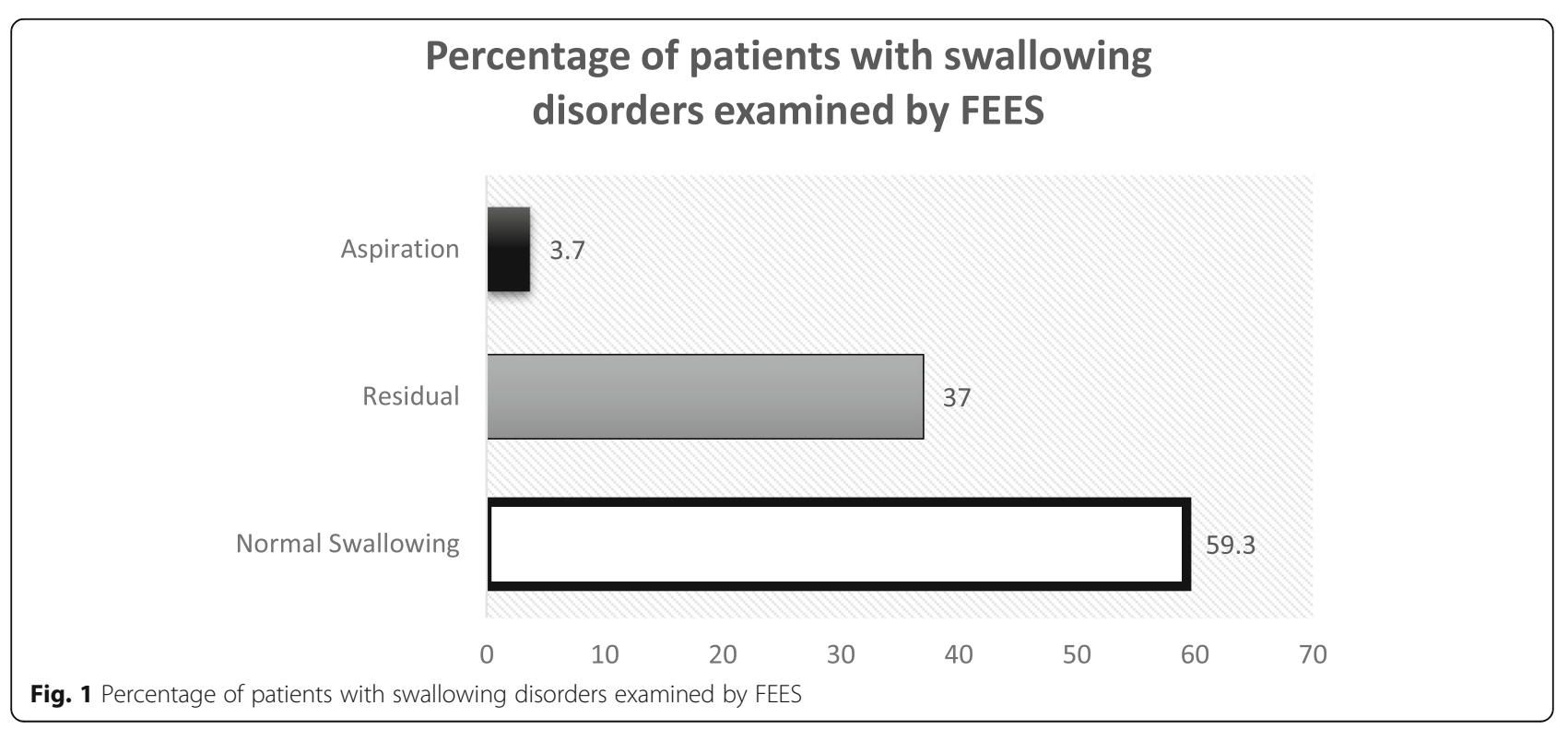


Table 2 Comparison of the baseline characteristics between subjects with and without dysphagia based on FEES

\begin{tabular}{|c|c|c|c|}
\hline & $\begin{array}{l}\text { Normal swallowing } \\
N=32\end{array}$ & $\begin{array}{l}\text { Dysphagia } \\
N=22\end{array}$ & $P$ value \\
\hline Age (mean \pm SD) & $63.50 \pm 5.9$ & $60.55 \pm 4.8$ & 0.058 \\
\hline Sex & & & 0.753 \\
\hline Male & $22(57.9 \%)$ & $16(42.1 \%)$ & \\
\hline Female & $10(62.5 \%)$ & $6(37.5 \%)$ & \\
\hline $\begin{array}{l}\text { Disease duration } \\
\text { (mean } \pm \text { SD) }\end{array}$ & $4.38 \pm 2.1$ & $5.36 \pm 2.1$ & 0.106 \\
\hline \multicolumn{4}{|l|}{ Disease severity } \\
\hline Parkinsonism phenotype & & & 0.022 \\
\hline Tremor dominant & $30(65.2 \%)$ & $16(34.8 \%)$ & \\
\hline $\begin{array}{l}\text { Postural instability } \\
\text { and gait instability }\end{array}$ & $2(25.0 \%)$ & $6(75.0 \%)$ & \\
\hline SDQ & & & $<0.001$ \\
\hline Normal & $28(87.5 \%)$ & $7(31.8 \%)$ & \\
\hline Dysphagia & $4(12.5 \%)$ & $15(68.2 \%)$ & \\
\hline Salivation & & & 0.5 \\
\hline Normal salivation & $9(28.1 \%$ & $8(36.4 \%)$ & \\
\hline Sialorrhea & $23(71.9 \%)$ & $14(63.6 \%)$ & \\
\hline MMSE (mean \pm SD) & $27.56 \pm 2.0$ & $25.8 \pm 1.0$ & 0.001 \\
\hline \multicolumn{4}{|l|}{ UPDRS } \\
\hline $\begin{array}{l}\text { UPDRS part II score } \\
\text { (mean } \pm \text { SD) }(68=\text { severe) }\end{array}$ & $11.25 \pm 3.0$ & $21.91 \pm 10.9$ & 0.000 \\
\hline $\begin{array}{l}\text { UPDRS part III score } \\
\text { (mean } \pm \text { SD) }(108=\text { severe) }\end{array}$ & $35.81 \pm 6.2$ & $40.00 \pm 24.5$ & 0.359 \\
\hline UPDRS total (mean \pm SD) & $55.19 \pm 10.4$ & $78.09 \pm 33.8$ & 0.001 \\
\hline $\begin{array}{l}\text { Modified Hoehn and } \\
\text { Yahr scale (mean } \pm \text { SD) }\end{array}$ & $1.813 \pm .5$ & $2.727 \pm .4$ & 0.000 \\
\hline
\end{tabular}

MMSE Mini-Mental State Examination, UPDRS Unified Parkinson's Disease Rating Scale, SDQ swallowing disturbance questionnaire

The percentage of dysphagia in PIGD and TD type was 75 and $34 \%$, respectively, with a $P$ value equal to 0.02 .

SDQ was significantly correlated with the objective FEES ( $P$ value $<0.001)$ which means that the simple SDQ can be a screening tool replacing the less available FEES Table 2.

The mean MMS examination in dysphagia group is significantly lower (but still within normal range) than the normal group $(25.8 \pm 1.0$ versus $27.56 \pm 2.0$ with a $P$ value $=0.001)$.

Dysphagia was significantly correlated with UPDRS part II score, UPDRS part III score, and modified Hoehn and Yahr scale Table 2.

Parkinsonism phenotype and activity of daily living (ADL) were independent predictors of dysphagia Table 3 and Fig. 2.

Most of our series have TD phenotype, but the percentage of dysphagia is significantly higher in PIGD phenotype Table 4.

\section{Discussion}

Normal swallowing depends on smooth coordination of the oral and pharyngeal phase. An impaired oral phase may impair the airway during the pharyngeal phase [25, 26].

The prolonged oral transit time which may be a factor that predispose to dysphagia in $\mathrm{PD}$, a finding reported from a radiological study [27].

Aspiration and pneumonia are common complications of dysphagia and may occur at any stage of PD but more with advanced stage [28].

More than $35 \%$ of patients experience dysphagia on SDQ, and this percentage increases to about $40 \%$ when using FEES which is similar to the results of previous studies which reported that the occurrence of dysphagia is between 20 and $40 \%$ in patients with IPD [16] in contrast to previous work of Manor and colleagues which stated a higher percentage of dysphagia (63.2\%) [3]; this difference may be related to the selection of patient as most of our participants are outpatients, and their $H \& Y$ scale was less than 3 which is classified as an early stage of IPD. Also, the mean duration of illness in our PD patients was 4.7 which means a relatively short duration of $\mathrm{PD}$.

Oral phase of dysphagia is more commonly affected than pharyngeal phase ( $24 \%$ versus $11.1 \%$ respectively) like other studies which confirmed the affection of oral phase more than pharyngeal phase of swallowing in PD [29].

Like previous studies, the present study revealed that dysphagia is significantly correlated with UPDRS and

Table 3 Predictors of dysphagia in PD

\begin{tabular}{|c|c|c|c|c|c|c|c|c|}
\hline & \multirow[t]{2}{*}{ B } & \multirow[t]{2}{*}{ S.E. } & \multirow[t]{2}{*}{ Wald } & \multirow[t]{2}{*}{$d f$} & \multirow[t]{2}{*}{ Sig. } & \multirow[t]{2}{*}{$\operatorname{Exp}(B)$} & \multicolumn{2}{|c|}{ 95\% C.I. for $\operatorname{EXP}(B)$} \\
\hline & & & & & & & Lower & Upper \\
\hline Parkinsonism phenotype & 1.947 & 0.913 & 4.543 & 1 & 0.033 & 7.007 & 1.170 & 41.973 \\
\hline Total UPDRS & -0.042 & 0.037 & 1.271 & 1 & 0.260 & .959 & 0.891 & 1.032 \\
\hline II_ADL & 0.330 & .144 & 5.232 & 1 & 0.022 & 1.391 & 1.048 & 1.846 \\
\hline Sialorrhea & 0.426 & 0.664 & .411 & 1 & 0.521 & 1.530 & .417 & 5.619 \\
\hline Constant & -3.546 & 1.675 & 4.480 & 1 & 0.034 & 0.029 & & \\
\hline
\end{tabular}




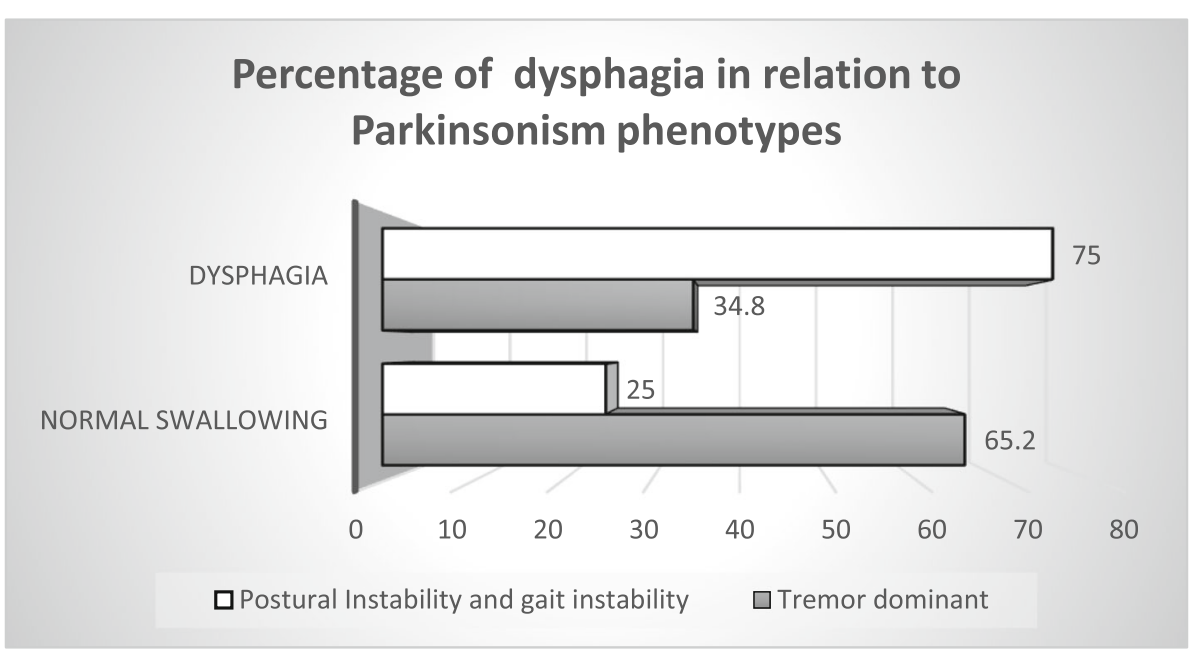

Fig. 2 Percentage of dysphagia in relation to parkinsonism phenotypes

modified Hoehn and Yahr scale [30, 31] in contrast to the others $[32,33]$ which showed that the disease stage (UPDRS total and Hoehn and Yahr rating) was not correlated to swallowing difficulties which may be explained by the relatively early stage of PD in our patients $(H \& Y$ scale $<3)$, the shorter duration of illness $(4.7 \pm 2.2)$ and the usage of different scores for evaluation of dysphagia.

The present work emphasized the greater percentage of dysphagia in PIGD group than tremor dominant group $(75 \%$ versus $34.8 \%$ respectively). This finding was in line with the previous studies which reported that dysphagia may be associated with more "axial" motor disturbance, increased postural instability, and more falls $[11,12]$.

The mechanism of dysphagia in PD may be related to extrapyramidal and autonomic system disorders into

Table 4 Dysphagia in relation to different phenotypes of parkinsonism

\begin{tabular}{clll}
\hline & $\begin{array}{l}\text { Tremor dominant (TD) } \\
N=46\end{array}$ & $\begin{array}{l}\text { Postural instability and } \\
\text { gait instability (PIGD) } \\
N=8\end{array}$ & $P$ value \\
\hline SDQ & & & 0.342 \\
Normal & $31(67.4 \%)$ & $4(50.0 \%)$ & \\
Dysphagia & $15(32.6 \%)$ & & 0.041 \\
Salivation & & $5(62.5 \%)$ & \\
Normal & $12(26.1 \%)$ & $3(37.5 \%)$ & 0.033 \\
Sialorrhea & $34(73.9 \%)$ & & \\
FEES & & $2(25.0 \%)$ & \\
Normal & $30(65.2 \%)$ & $6(75.0 \%)$ & \\
Dysphagia & $16(34.8 \%)$ & & \\
\hline
\end{tabular}

$S D Q$ swallowing disturbance questionnaire, FEES fiberoptic endoscopic evaluation of swallowing which degeneration of the dorsal nucleus of the vagus and esophageal myenteric plexus is responsible for dysphagia [34], and this neurodegeneration in the autonomic nervous system occurring not only in the late stage but also in the early stages of PD [35]; this finding may be confirmed by the fact that dysphagia is partially improved by dopaminergic therapy $[12,35,36]$.

Our results showed a strong correlation between PD severity on UPDRS and dysphagia, so the severity could be a predictor of dysphagia in PD patients like many previous studies with apparently larger sample sizes which documented the significant association between the severity of PD and dysphagia [15, 25, 26]. On the other hand, Ali and Wallace did not observe any correlation between the clinical severity of PD and dysphagia, which may be explained by a smaller sample size of their participants and most of their patients had advanced PD (H\&Y stage more than III) [37].

The major limitation of this study was the relatively small sample size and lack of follow-up of patients with dysphagia especially the asymptomatic group and the effect of different dopaminergic drugs on dysphagia.

In spite of these limitations, the present study has shown that dysphagia is a common symptom even in an early stage of PD. The simple and available SDQ may be a useful screening tool for detection of dysphagia in $\mathrm{PD}$ and the patients with abnormal SDQ better to be referred to a speech therapist.

\section{Conclusions}

In conclusion, the present work is one of few studies that exhibited the association between dysphagia and early PD and showed that dysphagia symptoms is more prevalent in PIGD phenotype. Dysphagia could be easily detected by SDQ and confirmed by FEES as the early 
detection of dysphagia decreases the deleterious impact on quality of life of PD patients.

\section{Appendix 1}

Drooling Severity and Frequency Scale (DSFS) considering the sum of the scores for severity (1, dry: never drools; 2, mild: only lips wet; 3 , moderate: lips and chin wet; 4, severe: clothing soiled; 5, profuse: clothing, hands, and tray moist wet) and frequency (1, never drools; 2, occasional drooling-not every day; 3 , frequent drooling-every day; 4, constant drooling) [23].

\section{Additional files}

Additional file 1: Swallowing disturbance questionnaire. (DOCX $15 \mathrm{~kb}$ )

\section{Abbreviations}

FEES: Fiberoptic endoscopic evaluation of swallowing; IPD: Idiopathic Parkinson's disease; MMSE: Mini-Mental State Examination; Modified H\&Y: Modified Hoehn and Yahr; PD : Parkinson's disease; PIGD: Postural instability/gait disorder; SDQ: Swallowing disturbance questionnaire; SPSS: Statistical Package for the Social Sciences; TD: Tremor dominant; UPDRS: Unified Parkinson's Disease Rating Scale

\section{Acknowledgements}

None.

\section{Funding}

None.

\section{Availability of data and materials}

The data set of this work is available and uploaded with this article.

\begin{abstract}
Authors' contributions
A-ABM choose the search idea; participate in the development of the research plan, conducting and applying the research; participate in the analysis and discussion of the results; and participate in the research review. GFM participate in the development of the research plan, participate in the analysis and discussion of the results, participate in writing research and participate in the research review. HME and MAS participate in the analysis and discussion of the results, participate in writing research, and participate in the research review. MMH and AMI participate in the analysis and discussion of the results and participate in the research review. SRA participate in the collection of scientific material. All authors read and approved the final manuscript.
\end{abstract}

\section{Ethics approval and consent to participate}

The study was approved by the local Ethical Committee of Sohag Faculty of Medicine, Sohag University on September 7, 2014, with reference number (75). Informed written (when available) consent was obtained from all patients for participation and publication of this study.

\section{Consent for publication}

This manuscript does not contain any personal data.

\section{Competing interests}

The authors declare that they have no competing interests.

\section{Publisher's Note}

Springer Nature remains neutral with regard to jurisdictional claims in published maps and institutional affiliations.

\section{Author details}

'Department of Neurology and Psychological Medicine, Sohag University, Sohag Governorate, Egypt. ${ }^{2}$ Phoniatric Unit, Faculty of medicine, Department of Otolaryngology, Sohag University, Sohag Governorate, Egypt.
Received: 16 November 2017 Accepted: 9 October 2018

Published online: 24 October 2018

\section{References}

1. De Rijk M, Breteler M, Graveland G, Ott A, Grobbee D, Van der Meche F, et al. Prevalence of Parkinson's disease in the elderly The Rotterdam Study. Neurology. 1995;45(12):2143-6.

2. de Rijk MC, Tzourio C, Breteler M, Dartigues J, Amaducci L, Lopez-Pousa S, et al. Prevalence of parkinsonism and Parkinson's disease in Europe: the EUROPARKINSON Collaborative Study. European Community Concerted Action on the Epidemiology of Parkinson's disease. J Neurol Neurosurg Psychiatry. 1997;62(1):10-5.

3. Manor Y, Giladi N, Cohen A, Fliss DM, Cohen JT. Validation of a swallowing disturbance questionnaire for detecting dysphagia in patients with Parkinson's disease. Mov Disord. 2007;22(13):1917-21.

4. Robbins AK, Whealy ME, Watson RJ, Enquist LW. Pseudorabies virus gene encoding glycoprotein $\mathrm{glll}$ is not essential for growth in tissue culture. J Virol. 1986:59(3):635-45.

5. Monte FS, da Silva-Júnior FP, Braga-Neto P, Nobre e Souza MA, Sales de Bruin VM. Swallowing abnormalities and dyskinesia in Parkinson's disease. Mov Disord. 2005;20(4):457-62.

6. Hartelius L, Svensson P. Speech and swallowing symptoms associated with Parkinson's disease and multiple sclerosis: a survey. Folia Phoniatrica et Logopaedica. 1994;46(1):9-17.

7. Kalf J, De Swart B, Bloem B, Munneke M. Prevalence of oropharyngeal dysphagia in Parkinson's disease: a meta-analysis. Parkinsonism Relat Disord. 2012;18(4):311-5.

8. Miller N, Noble E, Jones D, Burn D. Hard to swallow: dysphagia in Parkinson's disease. Age Ageing. 2006;35(6):614-8.

9. Suttrup I, Warnecke T. Dysphagia in Parkinson's disease. Dysphagia. 2016; 31(1):24-32.

10. Lam K, Kwai Yi Lam F, Kwong Lau K, Kay Chan Y, Yee Ling Kan E, Woo J, et al. Simple clinical tests may predict severe oropharyngeal dysphagia in Parkinson's disease. Mov Disord. 2007;22(5):640-4.

11. Walker RW, Dunn JR, Gray WK. Self-reported dysphagia and its correlates within a prevalent population of people with Parkinson's disease. Dysphagia. 2011;26(1):92-6.

12. Miller N, Allcock L, Hildreth A, Jones D, Noble E, Burn D. Swallowing problems in Parkinson disease: frequency and clinical correlates. J Neurol Neurosurg Psychiatry. 2009;80(9):1047-9.

13. Bird MR, Woodward MC, Gibson EM, Phyland DJ, Fonda D. Asymptomatic swallowing disorders in elderly patients with Parkinson's disease: a description of findings on clinical examination and videofluoroscopy in sixteen patients. Age Ageing. 1994;23(3):251-4.

14. Robbins JA, Logemann JA, Kirshner HS. Swallowing and speech production in Parkinson's disease. Ann Neurol. 1986;19(3):283-7.

15. Logemann JA, Blonsky ER, Boshes B. Dysphagia in parkinsonism. JAMA. 1975;231(1):69-70

16. Bushmann M, Dobmeyer SM, Leeker L, Perlmutter JS. Swallowing abnormalities and their response to treatment in Parkinson's disease. Neurology. 1989;39(10):1309

17. Hughes AJ, Daniel SE, Kilford L, Lees AJ. Accuracy of clinical diagnosis of idiopathic Parkinson's disease: a clinico-pathological study of 100 cases. J Neurol Neurosurg Psychiatry. 1992;55(3):181-4.

18. Van Hilten J, Van Der Zwan A, Zwinderman A, Roos R. Rating impairment and disability in Parkinson's disease: evaluation of the Unified Parkinson's Disease Rating Scale. Mov Disord. 1994;9(1):84-8.

19. Hoehn MM, Yahr MD. Parkinsonism onset, progression, and mortality. Neurology. 1967;17(5):427.

20. Folstein MF, Folstein SE, McHugh PR. "Mini-mental state": a practical method for grading the cognitive state of patients for the clinician. J Psychiatr Res. 1975;12(3):189-98.

21. Jankovic J, McDermott M, Carter J, Gauthier S, Goetz C, Golbe L, et al. Variable expression of Parkinson's disease. A base-line analysis of the DAT ATOP cohort. Neurology. 1990:40(10):1529.

22. Stebbins GT, Goetz CG, Burn DJ, Jankovic J, Khoo TK, Tilley BC. How to identify tremor dominant and postural instability/gait difficulty groups with the movement disorder society unified Parkinson's disease rating scale: comparison with the unified Parkinson's disease rating scale. Mov Disord. 2013;28(5):668-70 
23. Thomas-Stonell N, Greenberg J. Three treatment approaches and clinical factors in the reduction of drooling. Dysphagia. 1988;3(2):73-8.

24. Rosenbek JC, Robbins JA, Roecker EB, Coyle JL, Wood JL. A penetrationaspiration scale. Dysphagia. 1996;11(2):93-8.

25. Leopold NA, Kagel MC. Pharyngo-esophageal dysphagia in Parkinson's disease. Dysphagia. 1997;12(1):11-8

26. Leopold NA, Kagel MC. Prepharyngeal dysphagia in Parkinson's disease. Dysphagia. 1996;11(1):14-22.

27. Stroudley J, Walsh M. Radiological assessment of dysphagia in Parkinson's disease. Br J Radiol. 1991;64(766):890-3.

28. Logemann JA. The evaluation and treatment of swallowing disorders. Curr Opin Otolaryngol Head Neck Surg. 1998;6(6):395-400.

29. Nagaya M, Kachi T, Yamada T, Igata A. Videofluorographic study of swallowing in Parkinson's disease. Dysphagia. 1998;13(2):95-100.

30. Kim JS, Youn J, Suh MK, Kim TE, Chin J, Park S, et al. Cognitive and motor aspects of Parkinson's disease associated with dysphagia. Can J Neurol Sci. 2015:42(6):395-400 Epub 2015/11/10.

31. Ding X, Gao J, Xie C, Xiong B, Wu S, Cen Z, et al. Prevalence and clinical correlation of dysphagia in Parkinson disease: a study on Chinese patients. Eur J Clin Nutr. 2017; Epub 2017/07/13.

32. Clarke C, Gullaksen E, Macdonald S, Lowe F. Referral criteria for speech and language therapy assessment of dysphagia caused by idiopathic Parkinson's disease. Acta Neurol Scand. 1998;97(1):27-35.

33. Coates C, Bakheit A. Dysphagia in Parkinson's disease. Eur Neurol. 1997;38(1): $49-52$.

34. Wakabayashi K, Takahashi H. Neuropathology of autonomic nervous system in Parkinson's disease. Eur Neurol. 1997;38(Suppl. 2):2-7.

35. Potulska A, Friedman A, Królicki L, Spychala A. Swallowing disorders in Parkinson's disease. Parkinsonism Relat Disord. 2003;9(6):349-53.

36. Hunter P, Crameri J, Austin S, Woodward M, Hughes A. Response of parkinsonian swallowing dysfunction to dopaminergic stimulation. J Neurol Neurosurg Psychiatry. 1997;63(5):579-83.

37. Ali G, Wallace K, Schwartz R, DeCarle D, Zagami A, Cook I. Mechanisms of oral-pharyngeal dysphagia in patients with Parkinson's disease. Gastroenterology. 1996;110(2):383-92.

\section{Submit your manuscript to a SpringerOpen ${ }^{\circ}$ journal and benefit from:}

- Convenient online submission

- Rigorous peer review

- Open access: articles freely available online

High visibility within the field

- Retaining the copyright to your article

Submit your next manuscript at $\boldsymbol{\nabla}$ springeropen.com 